\title{
Variantes somaclonais da cultivar de arroz Bluebelle resistentes à brusone ${ }^{(1)}$
}

\begin{abstract}
Leila Garcês de Araújo ${ }^{(2)}$, Anne Sitarama Prabhu ${ }^{(3)}$, Marta Cristina Filippi ${ }^{(3)}$ e Wilson Ferreira de Oliveira ${ }^{(4)}$
Resumo - A brusone, causada por Pyricularia grisea, constitui fator limitante da produtividade do arroz irrigado, principalmente no Estado do Tocantins. A deteç̧ão de variabilidade genética quanto à resistência à brusone em cultivares suscetíveis, como a Bluebelle, considerada uma das cultivarespadrões quanto à qualidade dos grãos, foi o principal objetivo deste trabalho. O procedimento adotado incluiu a indução de calos provenientes de panículas imaturas, regeneração, avaliação e seleção das plantas $\mathrm{R}_{2}$ resistentes à doença. $\mathrm{O}$ mesmo procedimento foi utilizado para nova indução de calos e regeneração de plantas a partir de três plantas $\mathrm{R}_{2}$ selecionadas. Foi realizada a avaliação e a seleção de plantas resistentes nas gerações $R_{2}$ e $R_{4}$ em viveiro de brusone. Nos testes realizados em casa de vegetação com três isolados coletados da cultivar Metica-1, pertencentes aos patótipos IB-41 e IB-45 de $P$. grisea, todos os 47 somaclones $\mathrm{R}_{6}$ foram resistentes. Por outro lado, os somaclones apresentaram reações diferenciais frente a cinco isolados provenientes de somaclones da cultivar Bluebelle, e resistência a um isolado proveniente da cultivar Bluebelle, enquanto a cultivar Bluebelle foi suscetível a todos os isolados. Estes resultados indicaram variação genética no que diz respeito à resistência à brusone, na segunda fase de indução de calos e na regeneração de plantas. Dos 47 somaclones $\mathrm{R}_{6}, 22$ apresentaram alto grau de resistência vertical nos testes conduzidos nos viveiros de brusone em quatro locais, e poderão ser utilizados como novas fontes de resistência.
\end{abstract}

Termos para indexação: Oryza sativa, Pyricularia grisea, cultura de tecidos, variação somaclonal, resistência a doenças.

\section{Blast resistant somaclonal variants of rice cultivar Bluebelle}

\begin{abstract}
Rice blast, caused by Pyricularia grisea, is the major yield constraint in irrigated rice mainly in the State of Tocantins. The detection of genetic variability for blast resistance in susceptible cultivars such as Bluebelle, considered as a standard for superior grain quality, was the main objective of the present investigation. The adopted procedure included the induction of callus from the immature panicles, regeneration, evaluation and selection of $\mathrm{R}_{2}$ plants for blast resistance. The same procedure was repeated using three selected $\mathrm{R}_{2}$ plants. The disease assessment and selection of blast resistant plants were done in $R_{2}$ and $R_{4}$ generations in blast nursery. In greenhouse tests with three isolates obtained from the cultivar Metica- 1 belonging to pathotypes IB-41 and IB-45 of $P$. grisea, all of the 47 somaclones $\mathrm{R}_{6}$ were resistant. They showed differential reaction to five isolates of somaclones and were resistant to one isolate derived from cultivar Bluebelle, while cultivar Bluebelle was susceptible to all isolates. These results indicated genetic variation for blast resistance in second step of induction and regeneration of plants. Of these 47 somaclones $\mathrm{R}_{6}, 22$ showed a high degree of vertical resistance in blast nursery tests conducted at four locations and can be utilized as new blast resistant sources.
\end{abstract}

Index terms: Oryza sativa, Pyricularia grisea, tissue culture, somaclonal variation, disease resistance.

(1) Aceito para publicação em 11 de agosto de 2000.

(2) Embrapa-Centro Nacional de Pesquisa de Arroz e Feijão (CNPAF), Caixa Postal 179, CEP 75375-000 Santo Antônio de Goiás, GO. Bolsista do CNPq. E-mail: leilag@cnpaf.embrapa.br

(3) Embrapa-CNPAF. E-mail: prabhu@enpaf.embrapa.br, cfilippi@ppserver.tamu.edu

(4)Universidade Federal de Goiás (UFG), Caixa Postal 131, CEP 74001-970 Goiânia, GO. E-mail: oliveira@agro.ufg

\section{Introdução}

A Bluebelle é uma cultivar de arroz irrigado, introduzida dos Estados Unidos, que ocupou 50\% da área plantada no Rio Grande do Sul na década de 70, devido à qualidade superior de seus grãos e à precocidade (Silveira, 1985). Posteriormente, esta cultivar foi substituída por outras, por causa da sua alta suscetibilidade à brusone e da baixa produtividade. 
A brusone, cujo agente causal é o fungo Pyricularia grisea (Cooke) Sacc (sin. P. oryzae), constitui um dos fatores limitantes da produtividade do arroz irrigado. O melhoramento do arroz para resistência à brusone é uma das prioridades nacionais de pesquisa. Foram lançadas, até o momento, as cultivares Javaé e Rio Formoso, com alto grau de resistência. A durabilidade da resistência destas cultivares tem sido pequena, em razão da alta variabilidade do patógeno. A base genética das cultivares lançadas é estreita (Cuevas-Pérez et al., 1992), e as fontes de resistência envolvidas são limitadas a poucos genótipos. A indução de resistência nas cultivares suscetíveis, altamente produtivas e de boa qualidade de grãos, é pré-requisito para o melhoramento visando resistência às doenças.

A primeira citação sobre variantes somaclonais em plantas regeneradas foi descrita por Butenko et al. (1967), analisando regenerantes de culturas de calos de fumo. Foi criado, 14 anos mais tarde, o termo variação somaclonal, por Larkin \& Scowcroft (1981), para designar o surgimento de variantes genéticos a partir da cultura de células in vitro.

Fatores como tempo de cultura, número de subcultivos, fitorreguladores, tipo de explante, genótipo, composição do meio de cultura, nível de ploidia e mosaicismo são considerados agentes capazes de induzir variabilidade in vitro (Silvarolla, 1992).

A variação somaclonal é freqüente, está presente em diferentes espécies e gêneros (Larkin \& Scowcroft, 1981), e foi descrita em diferentes níveis de ploidia, em plantas de fecundação cruzada e autofecundação, em plantas de propagação vegetativa ou por sementes, em plantas cultivadas ou não. A variação somaclonal é causada por mudanças genéticas em características qualitativas ou quantitativas (Scowcroft et al., 1985). Um grande número de plantas de diversas culturas resistentes a diferentes patógenos têm sido obtidas a partir de cultivares suscetíveis (Fukui, 1983; Daub, 1986; Cheng-Zhang et al., 1988; Pachón, 1989; Xie et al., 1990; Bouharmont et al., 1991). Os estudos realizados na
Embrapa-Centro Nacional de Pesquisa de Arroz e Feijão (CNPAF), em Santo Antônio de Goiás, mostraram resultados promissores na indução de variabilidade genética quanto à resistência à brusone, proveniente de panículas imaturas das cultivares de arroz, Basmati-370, Araguaia e IAC-47 (Araújo, 1994; Araújo et al., 1997). Visando aumentar a freqüência de variantes para resistência a doenças, foram regeneradas plantas a partir de $F_{1}$ de cruzamentos entre cultivares suscetíveis e doadoras de resistência. Os resultados mostraram maior freqüência de plantas resistentes à brusone nos somaclones desenvolvidos a partir de $\mathrm{F}_{1} \mathrm{~s}$ do que nas cultivares suscetíveis (Araújo et al., 1998).

A variação somaclonal pode ser utilizada para indução de mutações genéticas, sem alterações indesejáveis na qualidade da cultivar original, por meio de curto período de indução de calos. Mutações gênicas foram comumente obtidas em somaclones, e uma das estratégias de melhoramento inclui a utilização da cultivar melhorada para incorporação de uma característica específica como resistência às doenças, mediante a cultura de tecidos. O incremento de variabilidade genética para características desejáveis pode ser obtido a partir de plantas $\mathrm{R}_{2}$ que não apresentaram grau de resistência adequado (Evans et al., 1984).

Este trabalho objetivou desenvolver somaclones de Bluebelle resistentes à brusone e examinar o incremento do grau de resistência à doença no segundo ciclo de seleção e avaliação.

\section{Material e Métodos}

Panículas imaturas, de 1 a $4 \mathrm{~cm}$ de comprimento e com espiguetas de coloração branca ou levemente amarela de plantas da cultivar Bluebelle, foram usadas como explante no laboratório de cultura de tecidos da Embrapa-CNPAF, para indução de calos e regeneração de plantas, de acordo com o método descrito por Xie et al. (1990). Foi utilizada a nomenclatura proposta por Yurkova et al. (1982), sendo $\mathrm{R}_{1}$ os regenerantes primários, e $\mathrm{R}_{2}, \mathrm{R}_{3}, \mathrm{R}_{4}, \mathrm{R}_{5}$ e $\mathrm{R}_{6}$, a primeira, segunda, terceira, quarta e quinta progênies autofecundadas. Os procedimentos para o desenvolvimento dos somaclones estão descritos no esquema seguinte: 


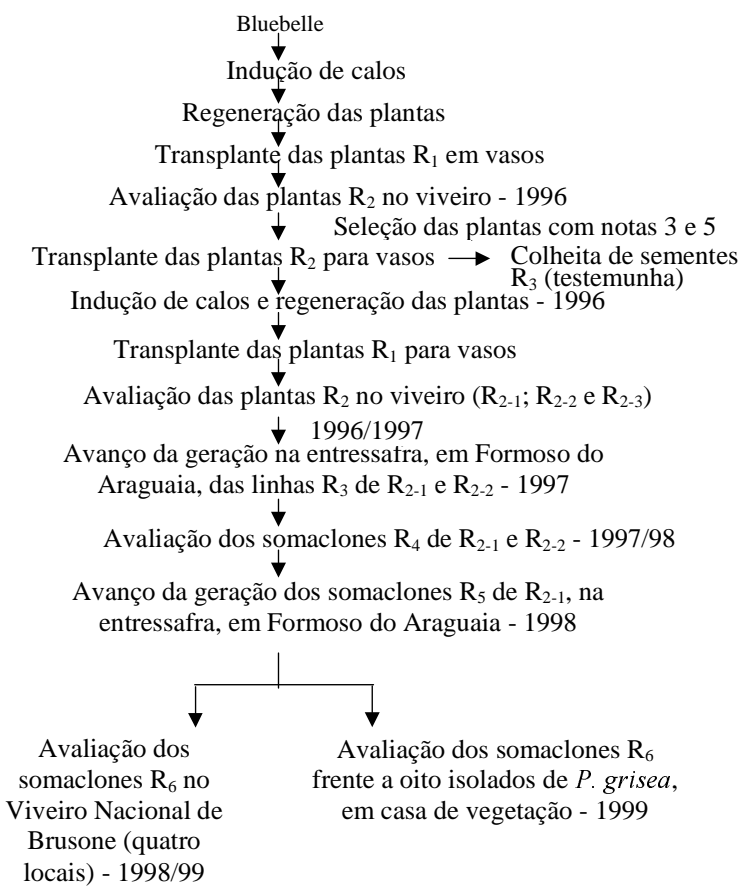

As plantas $R_{2}$, obtidas das plantas $R_{1}$ individuais, e a cultivar Bluebelle, foram avaliadas em viveiro de brusone, sob alta pressão de doença, em fevereiro de 1996. Na adubação, utilizaram-se $250 \mathrm{~kg} / \mathrm{ha}$ da fórmula 4-30-16 e $20 \mathrm{~kg} / \mathrm{ha}$ de sulfato de zinco. Cerca de 20 sementes de cada planta $\mathrm{R}_{1}$ foram semeadas em um sulco de $0,5 \mathrm{~m}$ de comprimento, totalizando seis sulcos. Uma bordadura formada pela mistura das cultivares suscetíveis IAC-47 e IAC 201 foi estabelecida 30 dias antes do plantio, para induzir a epidemia da doença. A avaliação da brusone foi realizada aos 34 dias após o plantio, por meio de uma escala visual de notas variando de 0-9 (International Rice Research Institute, 1988), onde, 0-3 indica reação resistente, e 4-9, reação suscetível. Foram selecionadas duas plantas $\mathrm{R}_{2} \mathrm{com}$ nota 3 (resistente) e uma com nota 5 (suscetível) que foram transplantadas para vasos com $6 \mathrm{~kg}$ de solo, para coleta de panícula imaturas, e mantidas até a maturação para colheita das sementes $\mathrm{R}_{3}$. Foi realizada uma nova indução de calos e regeneração de plantas, seguindo o método descrito anteriormente, a partir de plantas $\mathrm{R}_{2}$.

Para obtenção do segundo ciclo de seleção de indução e regeneração das plantas, foram regeneradas plantas $R_{1}$ a partir de cada planta $\mathrm{R}_{2}$ selecionada no viveiro de brusone. As plantas $R_{1}$ transplantadas em vasos, na casa de vegetação, foram denominadas $\mathrm{R}_{1-1}, \mathrm{R}_{1-2}$ e $\mathrm{R}_{1-3}$, respectivamente.
Em fevereiro de 1997, foram obtidas três populações $R_{2}$ a partir das plantas individuais $R_{1-1}$, $R_{1-2}$ e $R_{1-3}$, as quais foram denominadas de $R_{2-1}, R_{2-2}$ e $R_{2-3}$. Estas populações $R_{2}$ e a cultivar Bluebelle foram avaliadas no viveiro, na Estação Experimental Palmital, aos 45 dias após o plantio, utilizando o mesmo método descrito para avaliação em $\mathrm{R}_{2}$. A bordadura suscetível foi constituída por uma mistura de sementes das cultivares Bluebelle, BR-IRGA 409, Aliança e Cica 8. As plantas selecionadas foram transplantadas para vasos em casa de vegetação, onde permaneceram até a colheita das sementes $R_{3}$. As plantas $R_{3}$, obtidas por sementes de cada planta $R_{2}$ da primeira indução e regeneração, foram avaliadas nas mesmas condições.

A geração $R_{3}$ foi obtida pela multiplicação das sementes coletadas das plantas individuais $\mathrm{R}_{2}$ em julho de 1997 , em ensaio conduzido em Formoso do Araguaia. As sementes $\mathrm{R}_{4}$ de cada somaclone foram colhidas em "bulk" de 20 plantas.

Em fevereiro de 1998, 71 somaclones $\mathrm{R}_{4}$ da população $\mathrm{R}_{2-1}$ e 113 da população $\mathrm{R}_{2-2}$, bem como a cultivar Bluebelle, foram novamente avaliados no viveiro. Foram selecionados 47 somaclones com diferentes graus de resistência, sendo 30 resistentes (notas 1 a 3 ) e 17 suscetíveis (notas 4 e 7) da população $R_{2-1}$, e as sementes foram colhidas em "bulk" de 20 plantas, em cada somaclone $\mathrm{R}_{4}$. Na população $R_{2-2}$ não foi feita seleção, porque todas plantas apresentaram reações suscetíveis. A geração $R_{5}$ foi avançada da mesma maneira que em $\mathrm{R}_{3}$.

A geração $\mathrm{R}_{6}$ foi avaliada de duas maneiras, conforme demonstrado no esquema anterior. Uma parte da semente foi usada para avaliação dos 47 somaclones e da cultivar Bluebelle no Viveiro Nacional de Brusone (VNB), em quatro estações experimentais: Capivara, Palmital, Formoso do Araguaia e Pindamonhangaba. As reações da brusone nas folhas dos somaclones $\mathrm{R}_{4}$ em viveiro foram determinadas na mesma escala de 0 a 9 , descrita anteriormente. Os 47 somaclones $R_{6}$ e a cultivar Bluebelle foram também avaliados frente a oito isolados monospóricos de Pyricularia grisea, em condições de casa de vegetação. Estes isolados incluíram três obtidos da cultivar Metica-1 (patótipos IB-41 e IB-45), quatro dos somaclones que apresentaram notas visuais 4, 5 e 6 na Estação Experimental Palmital, e um da cultivar Bluebelle original. Os experimentos foram conduzidos em bandejas de plásticos de 30x10x15 cm, contendo $3 \mathrm{~kg}$ de solo adubado com $5 \mathrm{~g}$ de NPK (4-30-16), $1 \mathrm{~g}$ de sulfato de zinco e $2 \mathrm{~g}$ de sulfato de amônio na ocasião do plantio. Foi feita uma adubação de cobertura, 20 dias após a semeadura com $2 \mathrm{~g}$ de sulfato de amônio. As sementes dos 47 somaclones e da cultivar Bluebelle foram semeadas em bandejas de plástico, à razão 
de cinco bandejas por isolado. Cada bandeja continha dez sulcos, com 15 plantas por sulco. Também foram plantadas oito cultivares diferenciadoras internacionais, as quais receberam inóculo de cada isolado, para identificação dos patótipos. O primeiro experimento em casa de vegetação foi realizado com três isolados de Metica-1. O segundo foi feito com cinco isolados de somaclones, incluindo o de Bluebelle.

As plantas $\mathrm{R}_{6}$ receberam o inóculo aos 22 dias de idade, com uma suspensão contendo $3 \times 10^{5}$ esporos $/ \mathrm{mL}$ utilizando-se um pulverizador DeVillbiss № 15 (DeVillbiss, Health Care Division, Somerset, PA. 15501, USA), ligado a um compressor com pressão padronizada a $0,001 \mathrm{~kg} / \mathrm{cm}^{2}$. Após a inoculação, as plantas foram incubadas em câmara úmi$\mathrm{da}$, por 24 horas, e, posteriormente, transferidas para casa de vegetação com temperatura variando de 25 a $29^{\circ} \mathrm{C}$. As avaliações da brusone nas folhas foram feitas sete a nove dias após a inoculação, utilizando o número de lesões elípticas e esporulativas no perfilho principal de cada planta, e a escala visual de notas de 0 a 9 , modificada de Leung et al. (1988). Os patótipos foram identificados com base nas reações das oito diferenciadoras internacionais, conforme Atkins et al. (1967).

O tipo de grão do somaclone SCBB22 e de Bluebelle foi avaliado mediante a medição do comprimento, largura e espessura de 20 grãos por genótipo, com paquímetro. Foi feito o teste $t$ para testar a significância das médias.

\section{Resultados e Discussão}

A indução de calos foi iniciada seis dias após o cultivo de panículas imaturas in vitro. Os resultados obtidos foram semelhantes aos de Wu \& Zapata (1992) em outras cultivares de arroz. A máxima proliferação de calos ocorreu entre a terceira e quarta semana, resultando em freqüência média de indução de $87,5 \%$. A formação de raízes e parte aérea das plântulas no meio de cultura de regeneração iniciouse 10 a 15 e 15 a 20 dias após o início do cultivo, respectivamente, coincidindo com os resultados obtidos por Pachón (1989). A freqüência média de regeneração de plantas foi de $23,9 \%$. Não foi observada a ocorrência de plantas albinas, possivelmente devido à fonte do explante. Os regenerantes primários $\left(R_{1}\right)$ foram férteis, e não diferiram quanto ao tipo de planta da cultivar parental Bluebelle.

De um total de 62 plantas $\mathrm{R}_{2}$, provenientes de seis plantas $R_{1}$, oito apresentaram reação de resis- tência (nota 3), e duas, de suscetibilidade (nota 5), no viveiro. Por outro lado, a cultivar Bluebelle permaneceu altamente suscetível à brusone. As três linhas $R_{3}$ selecionadas no primeiro ciclo de seleção apresentaram-se suscetíveis à brusone (nota 5), no viveiro, em 1996/97. Isto indica que, para se conseguir alto grau de resistência à brusone com uma única fase de indução de calos e regeneração das plantas, o grau adequado de resistência da cultivar parental é muito importante. Os somaclones derivados das cultivares altamente suscetíveis, como Maratelli, e altamente resistentes, como Ramtulasi, não apresentaram variação somaclonal em relação à brusone, como relatado no trabalho por Araújo et al. (1998). Entretanto, estudos posteriores realizados por Araújo et al. (1999) mostraram que é possível produzir somaclones com alto grau de resistência à brusone, a partir de cultivares moderadamente resistentes, como a Araguaia.

Foram regeneradas 4,18 e 50 plantas $\mathrm{R}_{1}$, a partir de cada planta $R_{2}$ selecionada no viveiro de brusone. Os resultados da avaliação de brusone no viveiro das três populações $\mathrm{R}_{2-1}, \mathrm{R}_{2-2}$ e $\mathrm{R}_{2-3}$, obtidas de cada população $R_{1}$, são apresentados na Figura 1 . De um total de 213 e 143 plantas das populações $\mathrm{R}_{2-1}$ e $\mathrm{R}_{2-2}$, $19,5 \%$ e $46 \%$, respectivamente, apresentaram reações

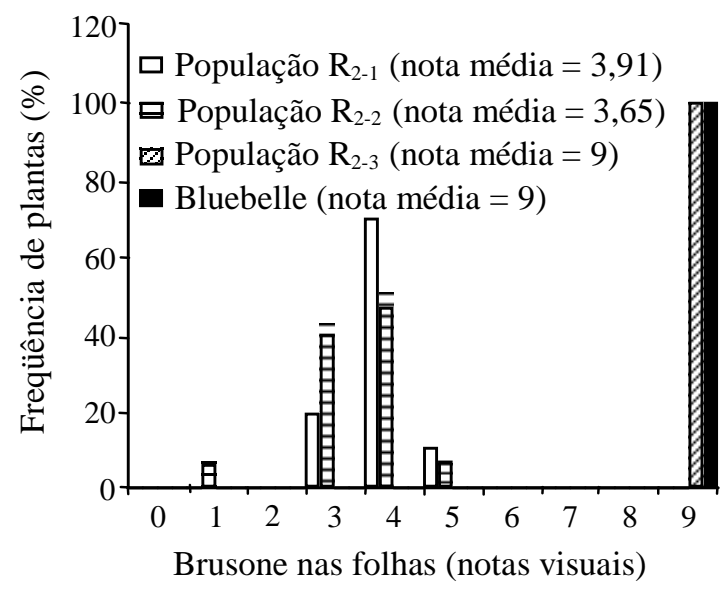

Figura 1. Freqüência de distribuição de plantas $\mathrm{R}_{2}$ de acordo com a resistência (notas 0-3) e susceptibilidade (notas 4-9) à brusone nas folhas de arroz em viveiro de brusone. 
resistentes (0-3), enquanto todas as 500 plantas da população $R_{2-3}$ e da cultivar Bluebelle exibiram reações altamente suscetíveis (nota 9).

As plantas $\mathrm{R}_{2}$ foram colhidas individualmente, $\mathrm{e}$ seus grãos apresentaram-se com coloração palha, e largura maior do que a dos grãos da cultivar Bluebelle original. A geração $R_{3}$ das populações $R_{2-1}$ e $R_{2-2}$ foi avançada na entressafra, e as linhas foram uniformes e férteis, mantendo o mesmo tipo de grão obtido na geração $R_{2}$.

Os resultados da avaliação de brusone no viveiro, da geração $R_{4}$ proveniente da população $R_{2-1}$, são apresentados na Figura 2. De um total de 71 somaclones $\mathrm{R}_{4}$ da população $\mathrm{R}_{2-1}, 42,1 \%$ exibiram reações de resistência, com graus que variaram de 1 a 3, enquanto a cultivar Bluebelle apresentou reação altamente suscetível (nota 9) nas mesmas condições. Todos os 113 somaclones $\mathrm{R}_{4}$ provenientes da população $R_{2-2}$ foram suscetíveis, embora com níveis menores de suscetibilidade (notas 5 e 7), em relação à cultivar Bluebelle. Todos os somaclones $\mathrm{R}_{4}$ das duas populações mostraram o mesmo tipo de grão de coloração palha, apresentado nas gerações anteriores. A geração $R_{5}$ da população $R_{2-1}$ foi avançada na

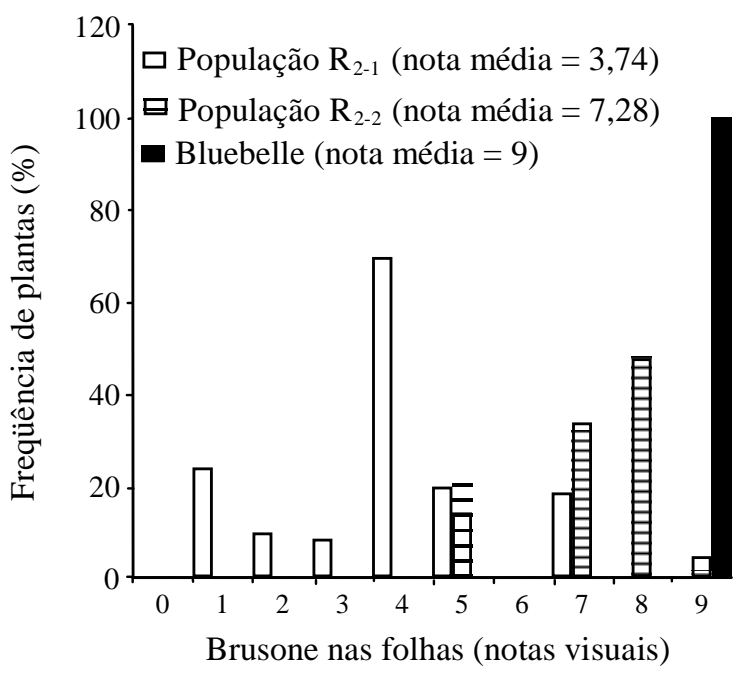

Figura 2. Freqüência de distribuição de plantas $\mathrm{R}_{4}$ de acordo com a resistência (notas 0-3) e susceptibilidade (notas 4-9) à brusone nas folhas de arroz em viveiro de brusone. entressafra, e as linhas foram uniformes e férteis, mantendo o mesmo tipo de grão observado nas gerações anteriores.

No primeiro experimento de casa de vegetação, com três isolados de $P$. grisea, dois pertencentes ao patótipo IB-41 e um ao patótipo IB-45, coletados na cultivar Metica-1, todos os 47 somaclones foram resistentes, enquanto a cultivar Bluebelle foi altamente suscetível.

No segundo experimento de casa de vegetação, entre os 47 somaclones avaliados frente aos quatro isolados, 22 foram resistentes, quatro foram suscetíveis, e 21 apresentaram reações diferenciais (Tabela 1). Todos os somaclones apresentaram-se resistentes ao isolado de Bluebelle, indicando, assim, mutação do gene para resistência. A cultivar Bluebelle foi suscetível a todos os isolados.

Os 22 somaclones mais resistentes obtidos em casa de vegetação também foram resistentes nos testes realizados no Viveiro Nacional de Brusone na fazenda Palmital, em Capivara, em Formoso do Araguaia e em Pindamonhangaba (Embrapa, 1999). Nos quatro locais, as reações dos somaclones foram variáveis, o que indica variabilidade na população do patógeno $P$. grisea em cada local, enquanto a cultivar Bluebelle apresentou reação suscetível em todos os locais.

Todos os somaclones apresentaram o grão de coloração palha, indicando variação genética na coloração do grão (Figura 3). O somaclone SCBB22 apresentou um comprimento médio de grão de $8,3 \mathrm{~mm}$ ( $s=0,30)$, sendo significativamente menor pelo teste $\mathrm{t}(\mathrm{p}<0,01)$ do que o da cultivar Bluebelle, com $9,12 \mathrm{~mm}(\mathrm{~s}=0,52 \mathrm{~mm})$. Por outro lado, no mesmo somaclone observou-se que a largura e a espessura média foi de 2,66 mm ( $\mathrm{s}=0,15 \mathrm{~mm})$ e $2,04 \mathrm{~mm}$ $(\mathrm{s}=0,07 \mathrm{~mm})$, respectivamente, sendo significativamente maiores pelo teste $\mathrm{t}(\mathrm{p}<0,01)$ do que a cultivar Bluebelle, que apresentou largura e espessura de $2,24 \mathrm{~mm}(\mathrm{~s}=0,13 \mathrm{~mm})$ e $1,90 \mathrm{~mm}(\mathrm{~s}=0,060 \mathrm{~mm})$, respectivamente. A variação de tipo de grão em plantas regeneradas de cultura de calos tem sido considerada alta (Zheng et al., 1989). Os resultados deste estudo indicam que as variabilidades desejáveis poderão ser obtidas tanto para características qualitati- 
Tabela 1. Reação de somaclones $\mathrm{R}_{6}$ de Bluebelle (SCBB) em relação a 5 isolados de Pyricularia grisea sob condições artificiais, em casa de vegetação, e em quatro locais no Viveiro Nacional de Brusone (VNB-1998/99)(1).

\begin{tabular}{|c|c|c|c|c|c|c|c|c|c|}
\hline \multirow[t]{2}{*}{ Genótipo } & \multicolumn{5}{|c|}{ Isolado $^{(2)}$} & \multicolumn{4}{|c|}{ Viveiro Nacional de Brusone (locais) } \\
\hline & ScPyl & ScPy8 & ScPy17 & ScPy26 & $B b P y$ & Palmital & Capivara & Formoso & Pindamonhangaba \\
\hline SCBB01 & 7 & 2 & 0 & 2 & 0 & 4 & 3 & 1 & 1 \\
\hline $\mathrm{SCBBO} 2^{(3)}$ & 2 & 2 & 2 & 2 & 0 & 3 & 3 & 1 & 1 \\
\hline $\mathrm{SCBBO3}^{(3)}$ & 2 & 2 & 0 & 2 & 0 & 3 & 3 & 1 & 1 \\
\hline SCBB04 & 9 & 7 & 7 & 9 & 0 & 5 & 4 & 1 & 4 \\
\hline SCBB05 & 9 & 9 & 7 & 9 & 0 & 9 & 4 & 2 & 4 \\
\hline SCBB06 & 9 & 9 & 5 & 5 & 0 & 4 & 4 & 2 & 4 \\
\hline $\mathrm{SCBB} 07^{(3)}$ & 2 & 2 & 2 & 2 & 0 & 3 & 3 & 2 & 1 \\
\hline SCBB08 & 2 & 7 & 2 & 2 & 0 & 5 & 3 & 2 & 7 \\
\hline $\mathrm{SCBB} 09^{(3)}$ & 2 & 0 & 2 & 2 & 0 & 3 & 3 & 1 & 1 \\
\hline $\operatorname{SCBB} 10^{(3)}$ & 2 & 2 & 2 & 2 & 0 & 3 & 3 & 1 & 1 \\
\hline SCBB $11^{(3)}$ & 2 & 2 & 2 & 2 & 0 & 3 & 3 & 1 & 1 \\
\hline SCBB12 & 2 & 5 & 2 & 2 & 0 & 3 & 3 & 1 & 1 \\
\hline SCBB13 & 2 & 5 & 2 & 2 & 0 & 3 & 3 & 1 & 4 \\
\hline SCBB14 & 2 & 2 & 5 & 2 & 0 & 3 & 3 & 1 & 4 \\
\hline SCBB15 & 5 & 5 & 2 & 2 & 0 & 3 & 4 & 1 & 4 \\
\hline SCBB16 & 0 & 2 & 5 & 2 & 0 & 3 & 3 & 1 & 1 \\
\hline $\operatorname{SCBB} 17^{(3)}$ & 2 & 2 & 2 & 0 & 0 & 3 & 3 & 1 & 3 \\
\hline SCBB $18^{(3)}$ & 2 & 2 & 2 & 2 & 0 & 3 & 3 & 1 & 1 \\
\hline SCBB19 ${ }^{(3)}$ & 2 & 2 & 2 & 2 & 0 & 3 & 3 & 1 & 1 \\
\hline SCBB20 $0^{(3)}$ & 2 & 2 & 2 & 2 & 0 & 3 & 3 & 1 & 1 \\
\hline SCBB21 & 2 & 9 & 9 & 9 & 0 & 9 & 4 & 2 & 8 \\
\hline SCBB22 $2^{(3)}$ & 2 & 2 & 2 & 2 & 0 & 3 & 3 & 1 & 1 \\
\hline SCBB23 & 2 & 9 & 2 & 2 & 0 & 7 & 3 & 1 & 4 \\
\hline SCBB24 & 2 & 9 & 7 & 7 & 0 & 9 & 3 & 1 & 4 \\
\hline SCBB25 & 2 & 0 & 9 & 5 & 0 & 2 & 3 & 1 & 4 \\
\hline SCBB26 & 0 & 0 & 2 & 5 & 0 & 6 & 3 & 3 & 4 \\
\hline SCBB27 & 0 & 0 & 7 & 2 & 0 & 3 & 3 & 1 & 1 \\
\hline SCBB28 $8^{(3)}$ & 0 & 2 & 2 & 2 & 0 & 3 & 3 & 2 & 3 \\
\hline SCBB29 $9^{(3)}$ & 0 & 2 & 2 & 2 & 0 & 3 & 3 & 1 & 1 \\
\hline $\mathrm{SCBB} 0^{(3)}$ & 0 & 0 & 2 & 2 & 0 & 3 & 3 & 2 & 1 \\
\hline SCBB31 & 5 & 2 & 2 & 2 & 0 & 4 & 3 & 2 & 1 \\
\hline SCBB32 $2^{(3)}$ & 0 & 2 & 2 & 2 & 0 & 3 & 3 & 1 & 1 \\
\hline SCBB33 & 7 & 9 & 9 & 2 & 0 & 9 & 3 & 2 & 1 \\
\hline SCBB34 & 5 & 2 & 2 & 2 & 0 & 3 & 3 & 2 & 4 \\
\hline SCBB35 & 7 & 9 & 7 & 2 & 0 & 4 & 3 & 3 & 1 \\
\hline SCBB36 $6^{(3)}$ & 2 & 2 & 2 & 2 & 0 & 2 & 3 & 1 & 3 \\
\hline SCBB37 $7^{(3)}$ & 2 & 2 & 2 & 2 & 0 & 2 & 3 & 2 & 1 \\
\hline SCBB38 & 5 & 2 & 2 & 2 & 0 & 2 & 1 & 2 & 4 \\
\hline SCBB39 $9^{(3)}$ & 2 & 2 & 2 & 2 & 0 & 2 & 1 & 1 & 1 \\
\hline SCBB40 $0^{(3)}$ & 0 & 2 & 2 & 0 & 0 & 3 & 1 & 1 & 1 \\
\hline SCBB $41^{(3)}$ & 0 & 2 & 2 & 2 & 0 & 2 & 1 & 1 & 1 \\
\hline $\mathrm{SCBB}_{42} 2^{(3)}$ & 0 & 2 & 2 & 2 & 0 & 3 & 1 & 2 & 1 \\
\hline SCBB43 $3^{(3)}$ & 2 & 2 & 2 & 2 & 0 & 3 & 1 & 1 & 1 \\
\hline SCBB44 & 5 & 2 & 2 & 2 & 0 & 2 & 1 & 1 & 4 \\
\hline SCBB45 & 2 & 2 & 2 & 7 & 0 & 3 & 1 & 2 & 4 \\
\hline SCBB46 & 9 & 9 & 9 & 2 & 0 & 9 & 1 & 2 & 4 \\
\hline SCBB47 & 5 & 9 & 7 & 9 & 0 & 5 & 1 & 2 & 4 \\
\hline Bluebelle & 9 & 9 & 9 & 9 & 9 & 9 & 9 & 9 & 4 \\
\hline Patótipo & IB-45 & IB-45 & IA-37 & IC-1 & IB-45 & - & - & - & - \\
\hline
\end{tabular}

(1) Notas 0 a 3: resistentes; notas 4 a 9: suscetíveis. ${ }^{(2)} S c P y l, S c P y 8, S c P y 17$ e $S c P y 26$; patótipos de somaclones de Bluebelle; BbPy: patótipo de Bluebelle. ${ }^{(3)}$ Somaclones que apresentaram reação resistente para cinco isolados de Pyricularia grisea e em quatro locais de teste no viveiro de brusone. 


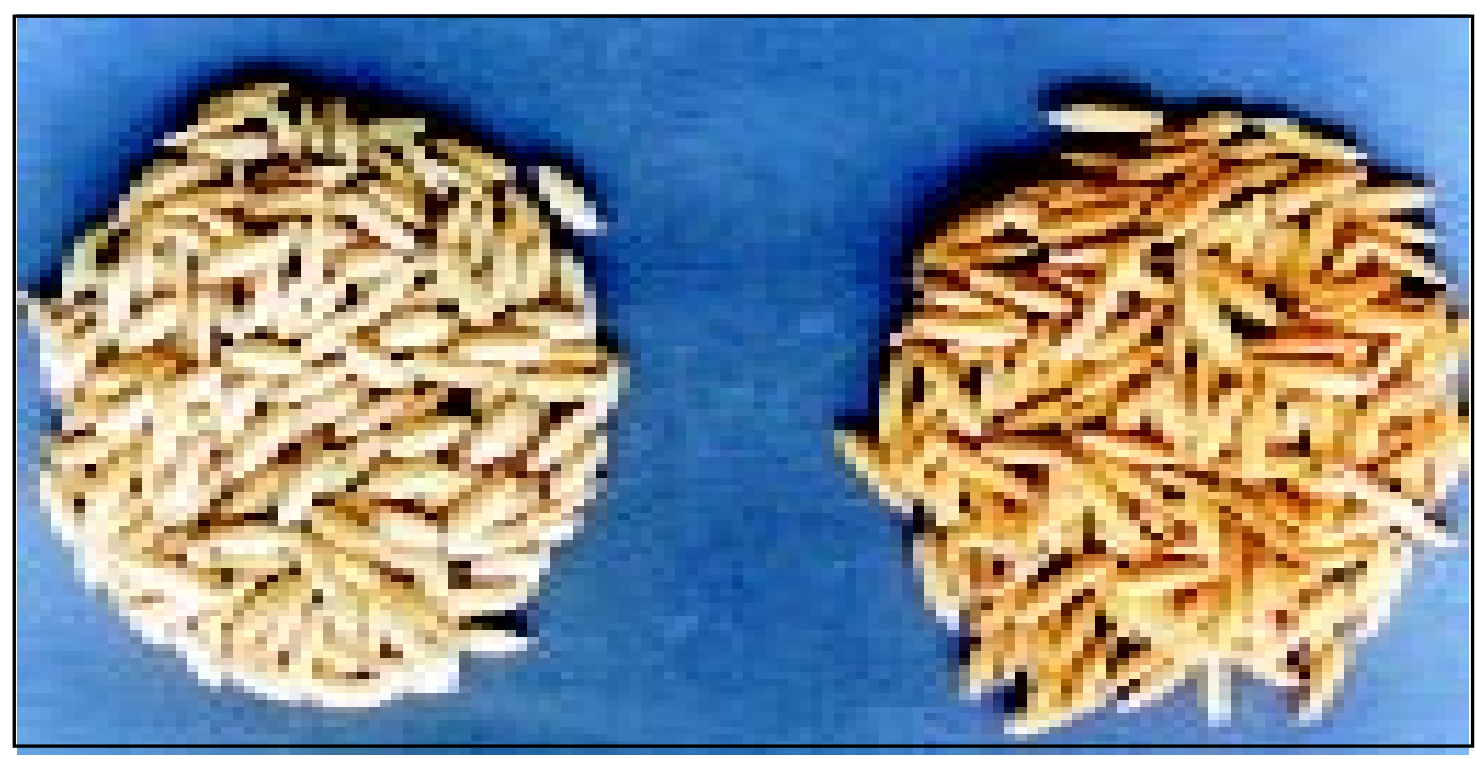

Figura 3. Tipo de grãos de arroz apresentados pelo somaclone SCBB22 de Bluebelle (esquerda), resistente à brusone, com grãos de coloração palha, e pela cultivar Bluebelle (direita), suscetível, com grãos de coloração dourada.

vas como para as quantitativas, as quais poderão ser utilizadas no melhoramento genético de arroz irrigado. A análise genética de quatro cultivares chinesas com diferentes tipos de grãos mostraram que o comprimento e o peso dos grãos dos somaclones foi reduzido, em comparação com os dos parentais, mas a variação da espessura e largura não foi evidente (Zheng et al., 1989). Neste estudo, obteve-se redução no comprimento do grão, aumento na largura e na espessura, e alteração da cor do grão. Quatro mutações para florescimento precoce, albinismo, encurtamento do colmo e esterilidade foram obtidas em 12 progênies de arroz regeneradas a partir de calos de sementes. Estas mutações foram acumuladas durante a fase de indução de calos e regeneração de plantas (Fukui, 1983).

Neste trabalho, as progênies $\mathrm{R}_{2}$ do primeiro ciclo de seleção apresentaram variabilidade quanto à resistência à brusone sob alta pressão da doença no viveiro, mas não foi adequada. As três plantas que apresentaram resistência moderada, e utilizadas para nova indução de calos e regeneração das plantas, mostraram maior variabilidade no tocante a todas características, incluindo resistência à brusone. $\mathrm{O}$ incremento nas variações desejadas foi obtido atra- vés do segundo ciclo de seleção, conforme o procedimento sugerido por Evans et al. (1984). Estes resultados mostraram a importância da indução e da regeneração, a partir de plantas nas gerações iniciais de cultivo de células.

\section{Conclusões}

1. Os somaclones de Bluebelle apresentam alto grau de resistência à Pyricularia grisea, e variação marcante na coloração do grão.

2. Os somaclones de Bluebelle podem ser utilizados como novas fontes de resistência à brusone no programa de melhoramento genético de arroz irrigado.

\section{Referências}

ARAÚJO, L. G. de. Variação somaclonal em arroz com relação à resistência à brusone. Goiânia : UFG, 1994 140 p. Dissertação de Mestrado.

ARAÚJO, L. G. de; PRABHU, A. S.; FILLIPI, M. C. Genetics analysis of leaf blast resistance in somaclones of rice cultivar Araguaia. Fitopatologia Brasileira, Brasília, v. 24, n. 2 , p. $182-184,1999$ 
ARAÚJO, L. G. de; PRABHU, A. S.; FREIRE, A. B. Variação somaclonal na cultivar de arroz IAC-47 para resistência à brusone. Fitopatologia Brasileira, Brasília, v. 22, n. 2, p. 125-130, 1997.

ARAÚJO, L. G. de; PRABHU, A. S.; FREIRE, A. B. Variation for rice blast resistance in early somaclonal generations derived from immature panicles. Pesquisa Agropecuária Brasileira, Brasília, v. 33, n. 8, p. 1349 1359, ago. 1998.

ATKINS, J. C.; ROBERT, A. L.; ADAIR, C. R.; GOTO, K.; KOZOKA, T.; KANOGITA, R.; YAMADA, M.; MATSUMOTO, S. An international set of rice varieties for differentiating races of Pyricularia oryzae. Phytopathology, St. Paul, v. 57, p. 297-301, 1967.

BOUHARMONT, J.; DEKEYSER, A.; SINT JAN, V. van; DOGBE, Y. S. Application of somaclonal variation and in vitro selection to rice improvement. In: INTERNATIONAL RICE RESEARCH INSTITUTE (Los Baños, Filipinas). Rice genetics II. Manila, 1991. p. 271-277.

BUTENKO, R. G.; SHEMINA, Z. B.; FROLOVA, L. V. Induced organogenesis and characteristics of plants produced in tobacco tissue culture. Genetika, Moscow, v. 3 , p. $29-39,1967$

CHENG-ZHANG, Z.; KANGE-LE, Z.; ZONG-XIU, S.; XIU-FANG, Q. Somaclonal variation and rice improvement. In: INTERNATIONAL RESEARCH INSTITUTE (London, Inglaterra). Genetic manipulation in crops. London : C. Tycooly, 1988, p. 115-116.

CUEVAS-PÉREZ, F. E.; GUIMARÃES, E. P.; BERRIO, L. E.; GONZÁLES, D. I. Genetic base of irrigated rice in Latin America and the Caribbean, 1971 to 1989. Crop Science, Madison, v. 32, n. 4, p. 1054-1059, 1992.

DAUB, M. E. Tissue culture and the selection of resistance to pathogens. Annual Review of Phytopathology, Palo Alto, v. 24, p. 159-186, 1986.

EMBRAPA. Centro Nacional de Pesquisa de Arroz e Feijão (Goiânia, GO). Viveiro nacional de brusone (VNB 98). Goiânia, 1999. 100 p. (Relatório, 17).

EVANS, D. A.; SHARP, W. R.; MEDINA FILHO, H. P. Somaclonal and gametoclonal variation. American Journal of Botany, Columbus, v. 71, n. 6, p. 759-774, 1984.

FUKUI, K. Sequential occurrence of mutation in a growing rice callus. Theoretical and Applied Genetics, Berlin, v. 65 , p. 225-230, 1983.
INTERNATIONAL RICE RESEARCH INSTITUTE (Los Baños, Filipinas). Standard evaluation system for rice. 3. ed. Los Baños, 1988. 54 p.

LARKIN, P. J.; SCOWCROFT, W. R. Somaclonal variation a novel source of variability from cell cultures for plant improvement. Theoretical and Applied Genetics, Berlin, v. 60, p. 197-214, 1981.

LEUNG, H.; BORROMEO, E. S.; BERNARDO, M. A.; NOTTEGHEM, J. L. Genetic analysis of virulence in the blast fungus Magnoporthe griseae. Phytopathology, St. Paul, v. 78, p. 1227-1233, 1988.

PACHÓN, J. G. Evaluación del uso potencial de la variación somaclonal en el mejoramiento de algunos caracteres de importancia económica en el arroz (Oryza sativa L.). Bogotá : Pontificia Universidad Javeriana, 1989. $94 \mathrm{p}$.

SCOWCROFT, W. R.; DAVIS, P.; RYAN, S. A.; BRETTELL, R. I. S.; PALLOTTA, M. A.; LARKIN, P. J. The analysis of somaclonal mutants. In: FREELING, M.; ALAN, R. (Ed.). Plant genetics. New York : Academic, 1985. p. 799-815.

SILVAROLLA, M. B. Plant genomic alterations due to tissue culture. Journal of the Brazilian Association for the Advancement of Science, São Paulo, v. 44, n. 5, p. 329-335, 1992.

SILVEIRA, E. P. Melhoramento genético: outro fator decisivo na produtividade do arroz gaúcho. Lavoura Arrozeira, Porto Alegre, v. 38, n. 357, p. 3-13, 1985.

WU, C.; ZAPATA, F. J. Plant regeneration from protoplasts isolated from primary callus of four japonica rice (Oryza sativa L.) varieties. Plant Science, Limerick, v. 86, p. $83-87,1992$.

XIE, Q. J.; RUSH, M. C.; CAO, J. Somaclonal variation for disease resistance in rice (Oryza sativa L.). In: GRAYSON, B. T.; GREEN, M. B.; COPPING L. G. (Ed.). Pest management on rice. London : Elsevier Applied Science, 1990. p. 491-509.

YURKOVA, G. N.; LEVENKO, B. A.; NOVOZHJLOV, P. V. Plant regeneration in wheat tissue culture. Biochemie und Physiologie der Pflanzen, Jena, v. 177, p. 337-344, 1982.

ZHENG, K. L.; ZHAN, Z. M.; WANG, G. L.; LUO, Y. K. Somatic cell culture of rice cultures with different grain types. Somaclonal variation in some grain and quality characters. Plant Cell, Tissue and Organ Culture, Dordrecht, v. 18, p. 201-208, 1989. 